Proc. Indian Acad. Sci. (Earth Planet. Sci.), Vol. 89, Number 2, July 1980, pp. 145-151. (C) Printed in India.

\title{
Measurement of recharge rates in soils through detection of tritium produced in Chinese thermonuclear tests
}

\author{
R N ATHAVALE and C S MURTI \\ National Geophysical Research Institule, Hyderabad 500 007, India
}

MS received 4 October 1979 ; revised 3 April 1980

\begin{abstract}
Variations in environmental tritium and moisture content with depth was measured at threo sites in sandy-loam and sandy-clay-loam soils, sampled near Hyderabad in May 1974. The tritium input function for procipitation around Hyderabad for the years 1969 to 1973 was determined through measurements on available rain samples and through extrapolation of strontium-90 data for HASL network station at Rawalpindi.

Three peaks noticed in the tritium input function and probably caused by Chinese thermonuclear tests in 1970, 1971 and 1972, could te matched with those sequentially identified in the soil profiles. This identification has helped in dating the soil moisture and in calculation of average annual recharge to groundwater. The recharge was found to be $15.4 \mathrm{~cm}$ and $14.6 \mathrm{~cm}$ for sandy-loam and $11.1 \mathrm{~cm}$ for sandy-clay-loam soils.
\end{abstract}

Keywords. Environmental tritium; thermonuclear tests ; soil profile ; recharge.

\section{Introduction}

Tritium activities, far exceeding the cosmic ray production level, were first measured in the Northern Hemisphere in 1954, after the 'Castle' series of thermonuclear tests in atmosphere (Begemann and Libby 1957). The environmental tritium levels increased with continued thermonuclear tests and reached a peak value in global precipitation of 1963 , after the tests at Noveya Zemalya USSR, in August 1962 (Payne and Halevey 1968). Bomb-produced tritium has been useful in investigations of age of groundwater, estimation of recharge and few other geohydrological problems (Drost et al 1974). Concentrations of tritium in global precipitations of 1963 were found to be higher than the natural cosmic ray level by a factor of 100 to 1000 , and also higher than the 1962 and 1964 levels by an order of magnitude. This fact has been utilised in the estimation of recharge to groundwater through soils. Assuming a piston-flow model for movement of water in the unsaturated zone, it was demonstrated in West Germany that the 1963 high in tritium level can be detected at various depths in soil profiles, depending upon the soil type, rainfall and other climatic controls (Zimmermann et al 1966 : Munnich 1968). The amount of water stored in a soil column, above 
the 1963 peak, gives a measure of cumulative recharge due to total rainfall, since the year 1963 upto the time of sampling. This method of recharge measurement was subsequently applied in UK, India and Denmark (Smith et al 1970; Sukhija and Rama 1973; Anderson and Sevel 1974).

As a result of the moratorium on testing of nuclear weapons in atmosphere by USA and USSR, the levels of tritium, strontium -90 and other bomb-produced nuclides in precipitation showed a gradual decline after the 1963 peak. However, the atmospheric tests of comparatively moderate yield (1-3 MT) thermonuclear devices, started by Peoples Republic of China since 1967, have given rise to second order peaks superimposed on the general declining trend in the stratospheric concentration of radionuclides in Northern Hemisphere. Various thermonuclear tests conducted by China during 1969-73 are listed in table 1 and the effect of these tests on strontium-90 fallout in Northern Hemisphere is shown in figure 1 (Leifer et al 1976).

Table 1. Atmospheric thermonuzlear tests by China during 1969-73.

Site : Lop Nor, $40^{\circ} \mathrm{N}: 90^{\circ} \mathrm{E}$

(After Carter and Mogh.issi 1977)

\begin{tabular}{rl}
\hline Date & $\begin{array}{l}\text { Yield in } \\
\text { kilotons }\end{array}$ \\
& \\
\hline $29-9-1969$ & $\sim 3000$ \\
$14-10-1970$ & $\sim 3000$ \\
$18-11-1971$ & $\sim 20$ \\
$7-1-1972$ & $<20$ \\
$18-3-1972$ & $20-200$ \\
$26-6-1973$ & $2000-3000$ \\
\hline
\end{tabular}

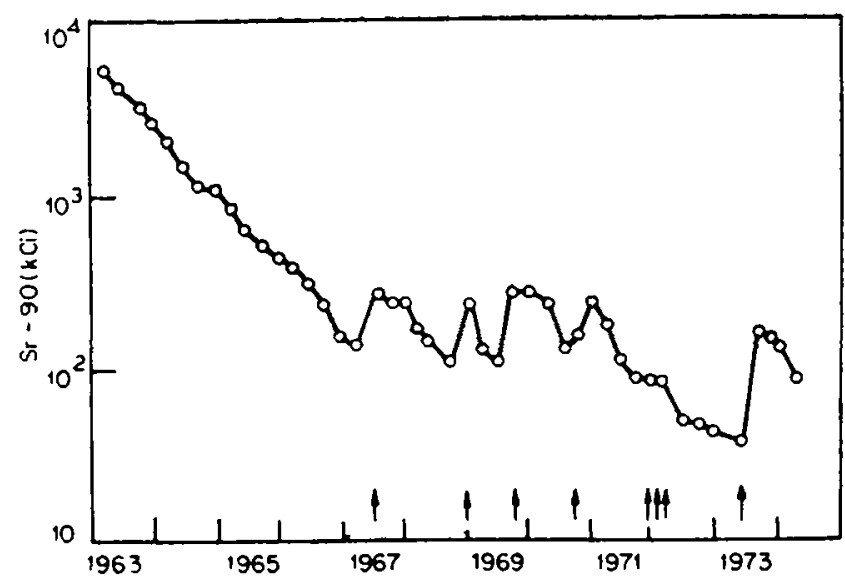

Figure 1. Stratospheric inventory of Sr-90 in northern bemisphere $\uparrow$ Chinese thermonuclear test. 
A similar effect on tritium levels has been observed (IAEA 1975) in the precipitation of continental stations such as New Delhi (28.58 N : 77.20 E), Jakutsk $(62 \mathrm{~N}: 130 \mathrm{E})$, Karizimir $(34.67 \mathrm{~N}: 69 \cdot 08 \mathrm{E})$ and Teheran $(35 \cdot 68 \mathrm{~N}: 51 \cdot 32 \mathrm{E})$.

Our studies in soils around Hyderabad $(17.45 \mathrm{~N}: 78.47 \mathrm{E})$ indicated that the transit time for the 1963 tritium peak in unsaturated zone was, in general, less than 8 to 10 years and the peak had moved up to the water table in many cases, the marker thus being lost for good (Athavale and Murti 1978). We have, therefore, attempted to make use of the second order tritium peaks introduced by Chinese tests, for the purpose of estimation of groundwater recharge.

\section{Tritium input in Hyderabad precipitation}

The tritium variation pattern in monthly precipitation at Hyderabad, for the years 1969 to 1973, is shown in figure 2. Monthly composite samples of precipitation at Hyderabad during the year 1973 were measured. The tritium levels in Hyderabad precipitation, for the years 1969 to 1972 , had to be estimated indirectly because of non-availability of samples. This was done through extrapolation of the Sr-90 data for precipitation at Rawalpindi (33.67 N : 73.13 E) in Pakistan.

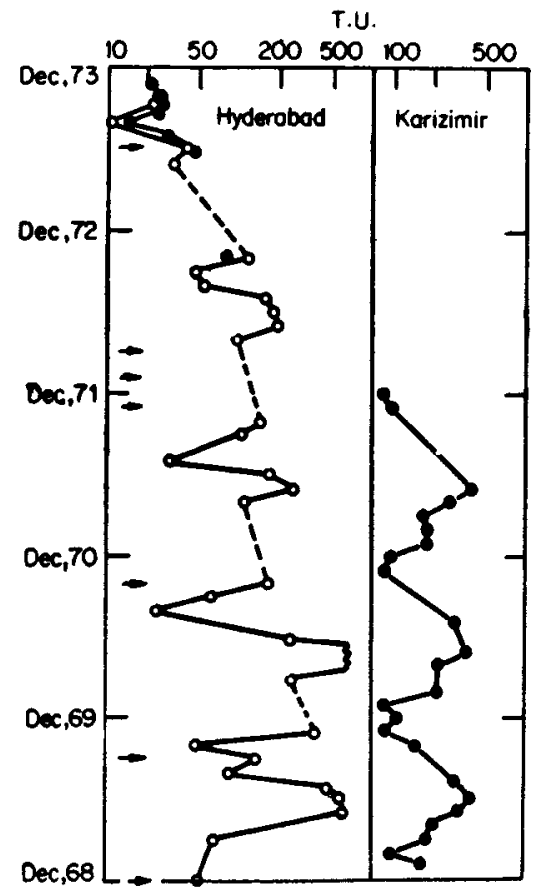

Figure 2. Tritium levels in precipitation at Hyderabad and Karizimir. - Measured tritium values for monthly composite samples of Hyderabad precipitation.

- Hyderabad tritium levels as extrapolated from Sr-90 data for Rawalpindi.

- Tritium levels in Karizimir precipitation.

$\uparrow$ Chinese thermonuclear test.

The dashed lines in Hyderabad input function represent periods of no rainfall. 
An average factor of 100 was observed for the ratio between measured $\mathrm{H}^{3}$ (T.U.) at Hyderabad and $\mathrm{Sr}-90(\mathrm{pCi} / 1)$ at Rawalpindi for the year 1973. This factor was used in deducing tritium levels in wet months at Hyderabad from the 1969 to 1972 Sr-90 data for Rawalpindi. The tritium levels at Karizimir, Afghanistan, which has a continuous record of monthly measurements during 1969 to 1971 , are also plotted in figure 2. The peaks in Hyderabad tritium input function (mostly reconstructed from $\mathrm{Sr}-90$ data) broadly match with those in the Karizimir data. Karizimir $(34.67 \mathrm{~N}: 78 \cdot 28 \mathrm{E})$ is located close to the site of the Chinese thermonuclear tests, which were carried out in the Lop Nor region $\left(40^{\circ} \mathrm{N}\right.$ : $90^{\circ} \mathrm{E}$ ). The correspondence of tritium peaks in Hyderabad and Karizimir input functions (figure 2), therefore, suggests that the tritium peaks in Hyderabad input function were caused by Chinese thermonuclear tests.

Atmospheric thermonuclear tests have been carried out by both China and France. Relevant details of these tests have been tabulated by Carter and Moghissi (1977) and by Carter (1979). It can be seen from these tables that, during the period 1969-73, the total number of Chinese thermonuclear tests was six and the cumulative yield was $\sim 9000 \mathrm{KT}$. France had carried out twentyone tests with a cumulative yield of only $\sim 3000 \mathrm{KT}$ over the same period. Most of the French tests were of low yield and only two tests, carried out in May and July 1970, were of $1000 \mathrm{KT}$ yield. Moreover, the French tests were carried out in Southern Hemisphere, at Mururoa and Fangatauffa atolls ( $21^{\circ} \mathrm{S}: 137^{\circ} \mathrm{W}$ ) and it can be assumed that a major fraction of the radioactive fallout was deposited in the Southern Hemisphere. A small fraction of the fallout did reach Northern Hemisphere in general and India in particular, through the process of interhemisphere mixing, as has been shown by Rangarajan et al (1970) and by Gopalakrishna and Rangarajan (1972). Thus, while we cannot rule out the possible contribution from French thermonuclear tests, it seems more likely that the tritium peaks in Hyderabad precipitation were caused by the Chinese thermonuclear tests.

\section{Tritium measurements in soil profiles}

Vertical soil profiles were collected in May 1974, from three sites located in Andhra Pradesh State. Two sites, namely Raikel (17.07 N:78.20 E) and Igaduru $(15.22 \mathrm{~N}: 77.95 \mathrm{E})$ were in sandy-loam soils and were sampled up to depths of $3.5 \mathrm{~m}$ and $2.4 \mathrm{~m}$ respectively. The third site, at village Thimmapuram $(15.5 \mathrm{~N}: 77 \cdot 55 \mathrm{E})$, in sandy-clay-loam soil, was sampled upto $2.2 \mathrm{~m}$ depth. Samples collected for every $10 \mathrm{~cm}$ interval, using a $6.25 \mathrm{~cm}$ dia hand-auger, were sealed in polythene bags. A $100 \mathrm{~g}$ fraction of each sample was used for gravimetric estimation of moisture content. The remaining fraction of the sample, weighing approximately $500 \mathrm{~g}$ was used for extracting the water sample used for tritium measurement. Eight cc of distilled water sample was converted into methane gas by the method described by Anand and Lal (1964) and Lal and Athavale (1966). The methane gas was purified further in a glass vacuum system and was filled in an Oeschger-type, low-level proportional gas counter which had a background count rate of $1.0 \pm 0.1 \mathrm{cpm}$ and a calibration factor of 
$75 \pm 7 \cdot 5 \mathrm{~T}$.U. per cpm at an operating voltage of $-4 \cdot 3 \mathrm{KV}$ and a filling pressure of $90 \mathrm{~cm} \mathrm{Hg}$. The tritium activity of each sample was counted for 1000 minutes duration approximately.

\section{Results and discussion}

Variation in tritium content at every $10 \mathrm{~cm}$ depth interval in the case of the $3.5 \mathrm{~m}$ soil pofile at Raikel is plotted in figure 3a. Using the same basic data, weighted tritium concentrations were also calculated for assumed soil sampling intervals of $20 \mathrm{~cm}, 30 \mathrm{~cm}, 40 \mathrm{~cm}$ and $50 \mathrm{~cm}$ length. Resulting shapes of tritium profiles can be seen in figures $3 b, c, d$ and e respectively. The soil tritium profile for $20 \mathrm{~cm}$ interval showed the best possible matching with the tritium input function (figure 4). A similars, one-to-one matching of all three peaks in input function with those in tritium profiles of $10,30,40$ and $50 \mathrm{~cm}$ interval was not found feasible and the fine structure peaks were not even discernible for the $50 \mathrm{~cm}$ interval.

Soil tritium profiles for the two other sites, Igaduru and Thimmapuram, were similarly plotted (figure 5) and peaks for the 1972 and 1971 rains could be identified in them.

Average annual recharge in the case of each profile was calculated in the following way. In the case of Raikel profile (figure 4), the 1970 peak was located at $3 \cdot 1 \mathrm{~m}$ depth. The total moisture content in the soil column up to this depth, representing cumulative recharge over a period of four years, was calculated to be $61.6 \mathrm{~cm}$, thus giving an average annual recharge figure of $15.4 \mathrm{~cm}$ or $23.8 \%$ of the average annual rainfall of $63.0 \mathrm{~cm}$. In the case of the other two soil profiles, at Igaduru and Thimmapuram, the 1971 peak could be identified at $2.3 \mathrm{~m}$ and $1.9 \mathrm{~m}$ depths respectively (figure 5). The corresponding annual average recharge figures were calculated as $14.6 \mathrm{~cm}$ and $11.1 \mathrm{~cm}$ or $25.6 \%$ and $19.5 \%$ respectively of the average annual rainfall of $57 \cdot 0 \mathrm{~cm}$.

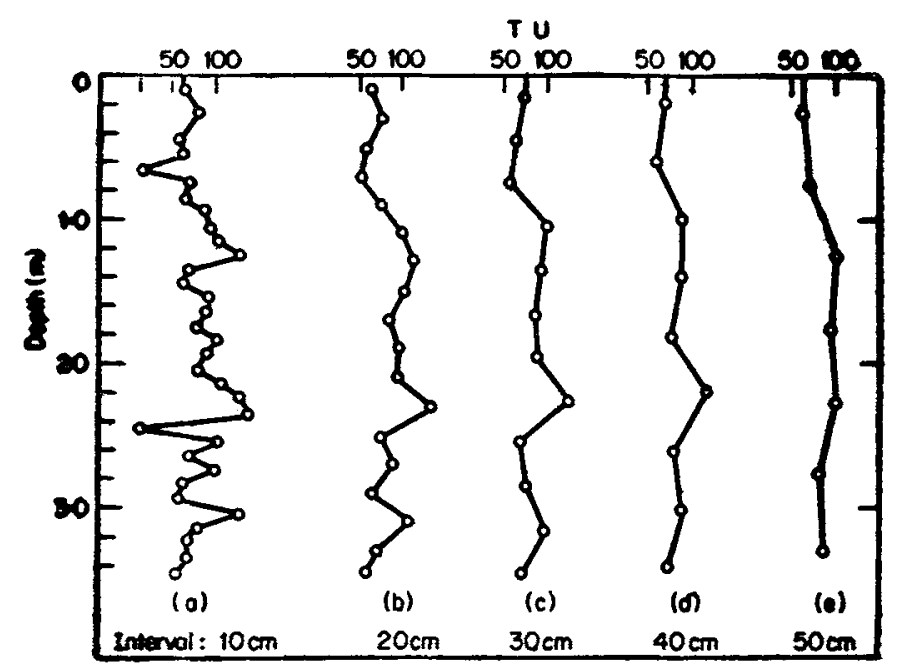

Figure 3. Variation in tritium concentration with depth for soil profile at Raikel $a$-measured values for $10 \mathrm{~cm}$ sampling interval; $b, c, d, e$-computed values for $20,30,40$ and $50 \mathrm{~cm}$ sampling interval, 


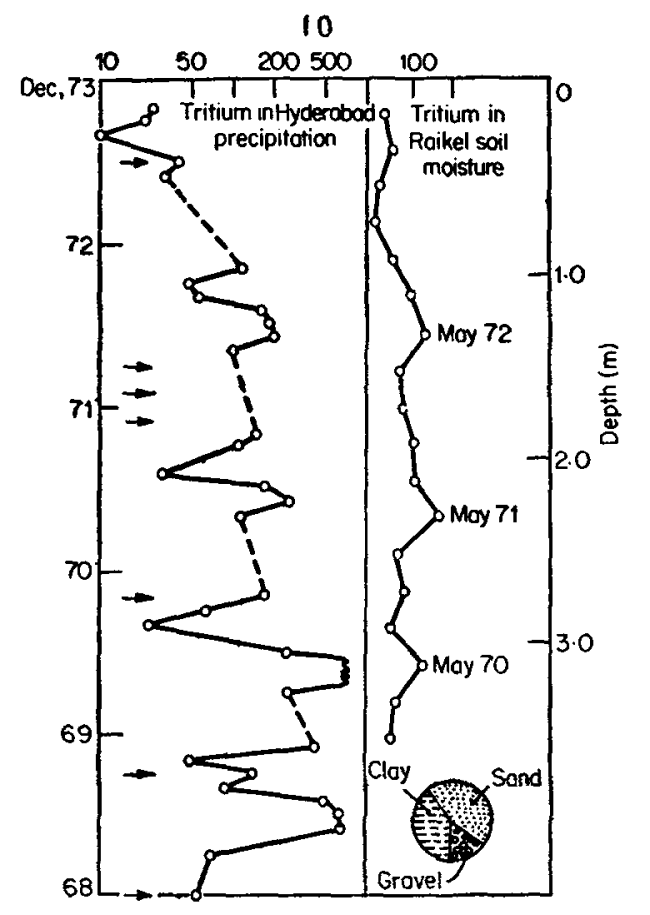

Figure 4. Matching of tritium peaks in soil moisture at Raikel with those in Hyderabad precipitation. Sector diagram indicates average soil composition in the profile. Soil tritium profile is for $20 \mathrm{~cm}$ interval.
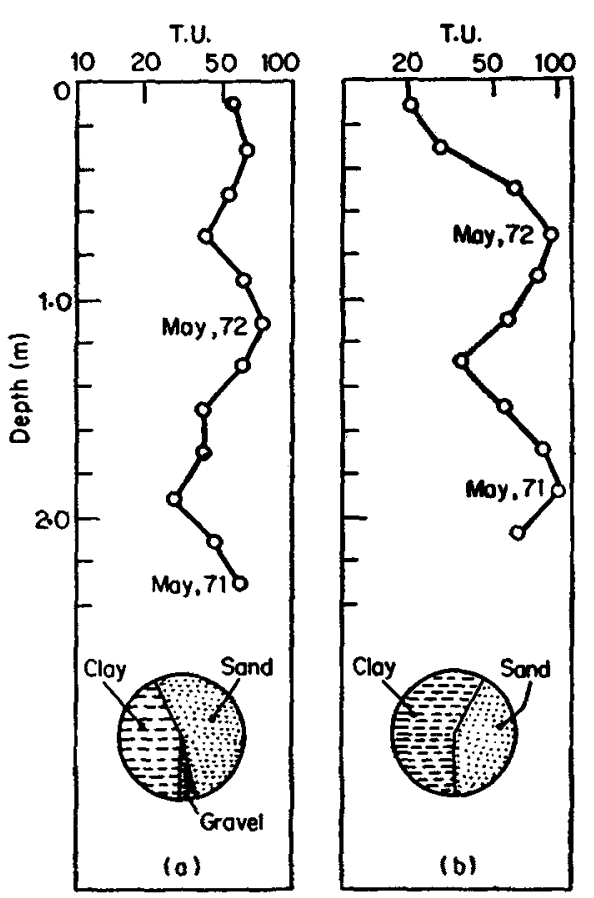

Figure 5. Tritium variation with depth in soil moisture at Igaduru (a) and Thimmapuram (b). Sector diagrams indcate average soil composition in the profiles. Soil tritium profile is for $20 \mathrm{~cm}$ interval.

\section{Conclusions}

(i) It was observed that the sampling interval is of critical importance in environmental tritium measurement for estimation of recharge through soils. In the particular cases studied by us, a $20 \mathrm{~cm}$ sampling interval was found to be optimal for correlation of tritium activities in the rain and soil moisture while a $50 \mathrm{~cm}$ sampling interval led to poor resolution and consequent difficulties in pattern recognition.

(ii) Tritium produced in Chinese atmospheric thermonuclear tests could be identified in soil moisture samples collected near Hyderabad. This identification has helped in dating the soil moisture and calculation of average annual recharge to groundwater.

\section{Acknowledgements}

We are thankful to Prof. S Bhagavantam for suggesting us to undertake tritium studies pertaining to the effect of Chinese thermonuclear tests. We are also thankful to the Director, Andhra Pradesh State Ground Water Department, for carrying out grain size analysis and classification of the soil profiles. 


\section{References}

Anand J S and Lal D 1964 Nature (London) 201775

Anderson $\mathrm{L} \mathrm{J}$ and Sevel T 1974 Isotopes in hydrology (Vienna, IAEA) p. 3

Athavale R N and Murti C S 1978 Approaches and methodologies for development of ground water resources, Proc. Indo-German Workshop, NGRI, Hyderabad p. 271

Begemann F and Libby W F 1957 Geochim. Cosmochim. Acta 12277

Carter M W 1979 Health Phys. 36432

Carter M W and Moghissi A A 1977 Health Phys. 3355

Drost W, Moser H, Neumaier F and Rauert W 1974 Isotopes method in groundwater hydrology, Eurisotop Monograph 16, Brussels, pp 89-97

Gopalkrishnan S and Rangarajan C 1972 J. Geophys. Res. 771012

International Atomic Energy Agency 1975 Environmental Isotope Data No. 5, Technical Report Series No. 165, Vienna

Lal D and Athavale R N 1966 Proc. Indian Acad. Sci. A63 166

Leifer R, Schonberg M and Toonkel L 1976 Report No. 306, Health and Safety Laboratory, U.S. Energy Research and Development Administration, New York p. 142

Munnich K O 1968 Guide book on nuclear techniques in hydrology (Vienna, IAEA) p. 191

Payne B R and Halevy E 1968 Guide book on nuclear techniques in hydrology (Vienna, IAEA) p. 7

Smith D B, Wearn P L, Richard H J and Rowe P C 1970 Isotopes in hydrology (Vienna : IAEA) p. 73

Rangarajan C, Gopalkrishnan S and Vohra K G 1970 J. Geophys. Res. 751753

Sukhija B S and Rama 1973 Proc. Indian Acad. Sci. A77 279

Zimmermann U, Munnich K O and Roether W 1966 Science 152346 